they project sufficiently to make contact and therefor close the circuit operating the induction coil.

If the magnet, 8 , is not excited and the disk is re volved the steel springs will slide within the ring and all the contact points will be open; if on the othe hand the key is closed and a current impulse is sent through the magnet, the steel springs sliding through the grove make connection with each of the contact points in passing them. The electrical connections be tween the steel springs and the contact points and the induction coil and oscillator system is clearly show by the dotted lines and it is evident that upon contact being established between a steel spring and the points the circuit will be closed and the current from the bat tery, 19, will operate the magnetic circuit closer, 20 thus causing the current from the battery, 21 , to flow through the primary of the induction coil, 22, when a disruptive discharge takes place through the spark gap and electric waves are emitted. Now for every current impulse that flows through the disperser magnet, 8 , by means of the key, 1, a series of electric waves are radiated, which equal the number of contact points, 18 and since the disks revolve at approximately constant speed the time intervals between a series of impulses will be proportional to the angular distances between the contact points, and thus by varying the distance between these points and by arranging these at different positions around the frame of the disperser the series of impulses or waves may be varied at will and within wide limits. When the electric waves thus emitted impinge upon the receiving antenna (Fig 5) the normally high resistance of the coherer is in stantly lowered and the local current flowing through the coherer and relay magnets, 23 , actuates its armature, closing an auxiliary circuit in which is included the decoherer, 24, for tapping the filings back to their normal resistivity, and the collector magnet, 25 , which s in shunt with the tapper. The collector, as th receiving mechanism is termed, is constructed on the same priaciples as the disperser, Fig. 3, in fact they may be substituted one for the other by means of prcper cut-outs. It will therefore be clear that for each series of impinging waves a steel spring is brought into the groove of the ring, 26. The disk of the collector, to which the steel springs are attached, revolves at a speed isochronous, practically, with that of the disk of the disperser; hence the angular distances between the springs brought into the groove will be lectric waves received by the antenna electric wave series are transmitted, five springs will be brought into the groove of the collector at angular intervals representing the intervals of time between the series of waves. The points, 27, making contact in the collector are arranged in the same relative positions as they are in the disperser, the springs moving in the groove forming the controlling contacts; these are connected in series with the Morse register, 28 , and consequently contact is made by all the points simultaneously. Now when the mutual angular value is the same for the points and the springs a prearranged series of electric waves will bring the latter into the groove, and as the disk revolves the series of steel springs, corresponding to the series of waves, will make contact simultaneously at all points;
the battery current operating the Morse register then flows through the circuit and prints a dot on the tape. A succession of wave series will produce a dash, or a row of dots reading as a dash. Wave series of or a row of dots reading as a dash. Wave series of
any other combination than those to which the collector is adjusted will not operate the Morse register for simultaneous contact is not possible and the circuit is left open.

In the experiments conducted by Mr. Bull only one transmitter and one receiver were employed, but the disperser was provided with three sets of contact points, 27, and was so arranged that any set desired could be operated by the induction coil, by means of a switch, and thus any one of three series of waves a switch, and thus any one of three series of waves
could be emitted and received at will. Uniformly with the diperser the collector was equipped with three sets of similarly arranged contact points, each set being connected with a Morse register, enabling the operators to use any one of three combinations to the exclusion of all others. Three series or combinations of waves only were required, as shown diagrammatically by $S^{1}, S^{2}$, and $S^{3}$, Fig. $6 A$. The element of time is
represented by the horizontal line and the wave series represented by the horizontal line and the wave series
or combinations by the vertical heavy strokes; the equi-distant spaces marked by the vertical lines designate 0.05 of a second. At $B$, Fig. 6 , is illustrated how the wave series are registered rhythmically when wireless wireless messe sent and received with accuracy and dispatch and were printed in Morse characters
on the tape of that register only for which it was in on the tape of that register only for which it was in-
tended, the other two machines remaining inoperative. Specimens of the tape from the three registers are shown at I., II., III., Fig. 6, each of the three series,
$S^{\prime}, S^{2}$. and $\mathcal{S}^{3}$, being employed successively. The speed attained aprroximated fifty letters per minute.
This is the first time in the history of wireless telegraphy that three messages have been transmitted and he first time in the history of the art that mechanica methods have been successfully employed in obtaining selectivity. The sending and receiving instruments may be set up at different points and at varying distances, which is a decided advantage over those sysems based on pure electrical resonance.

\section{THE PNEUMATIC TUBE SYSTEM OF A MODERN DEPARTMENT STORE.}

The use of pneumatic tubes in transmitting money, papers, and parcels of various kinds has become so extensive that the service is considered a necessity in he equipment of the modern mercantile establishment. The plan is not a new one. Improvements, however,
which have been made in the system in the last two or which have been made in the system in the last two or
three years have greatly increased its practical value In the dry goods or department store, for example, it is valuable as a labor saver, dispensing, as it does, with the many cash boys, in some instances cash girls, that have been employed, and performing their work much more quickly, besides avoiding many mistakes which formerly occurred. There is no delay in "making change," as the amount due the customer is usually handed him by the salesman within a minute, sometimes less than a minute, after his money has been taken over the counter. The system also assists in checking or auditing the sales, for the charge or cash slip which represents the amount of the transaction is sent to the cashier or bookkeeper, where it is examined and verified before being returned.

In the ordinary store the pneumatic tubes extend from the cashier's and bookkeeper's departments to the principal sales departments, varying, of course, in Each tube is termed a "line" and is usually $21 / 4$ inches in diameter. The tubes are generally extended along the ceiling or under the floors for the purpose of economizing space, and the terminals where the carriers are received and sent are of various shapes adjusted to suit the conditions. The system is so laid out that when a sale is made the clerk prepares his purchase check, gets the money from the purchaser, and places it in a small brass cylinder which can be unscrewed at the end merely by a twist of the fingers. the receiving end. The air forces it through the line to what is called the main station. This is usually in the cashier's office, for so many articles in the retail store are sold for cash that no entry is required. The carrier drops into the open receiver at the end of the tube, from which it is taken by the "change
maker" who, as already stated, glances over the fig. maker," who, as already stated, glances over the figbeen made, the slip and money are returned to the department from which they were sent. If correct, the slip is returned with the amount due the customer. If the sale is to be charged, the slip of course contains the name of the customer in addition to a description of the article and the amount due. As soon as it has been examined, the clerk in the cashier's office again places it in the carrier and inserts it in the tube or the memorandum is taken out, entered on the books, and either the original slip or a duplicate is returned to the salesman.

These operations are usually performed in less time than it takes to read the description; for the carrier travels at a rate varying from 1,000 to 2,500 feet pe minute, according to the air current. The length of line is seldom over 600 feet. The current is produced by the blower system, and the mechanical plant infourth to one-half horse power to each line, depending upon the number of bends or curves and the ing upon the number of bends or curves and the
amount of service. A store having a "50-line" service therefore requires an engine of about twenty-five horse power. In some systems the blowers are operated by steam power direct, but electric motors, either dire connected or bolted to the blowers, are preferred.

The air current is maintained in the tube system in the following manner: The various lines are conleads to the engine room and to the blowers. These blowers draw the air from the various sending terminals of the line, expelling it through a conduit of suit able size, which may open in the engine room or be connected with the street. While the velocity of the current varies according to the speed of the blower fans, the minimum is rarely less than 2,500 feet per ounces per square inch, the latter pressure being secured with a service of one-half horse power. The principle is simply the exhaustion of the air in the tubes to produce a partial vacuum. The effect is so powerful that, although the carriers and their contents weigh a half pound, they are transported without diff-
culty. The suction is not apparent twelve inches from the end of the receiver. Consequently, the end of the receiver can be placed over a desk or table on which light material, such as paper or currency, is spread. ncidentally the system is of considerable value from a hygienic standpoint, as it assists in the ventilation by continually changing the air in the apartment where he terminals are installed.

The carriers are merely cylinders of sheet brass cov ered at each end with felt to protect the metal from abrasion in passing around the elbows of the tube. They range from four to six inches in length for the ordinary store service, but do not fit closely against the side of the tube. Enough space is provided to allow the carrier to be borne along by the air current with little or no friction except at the turns, thereby permitting of a much greater speed than if the car rier acted as a piston and was continually in contact with the tubing. The receiving terminals are of two kinds, although both work automatically. The ones used in the cashier's and bookkeeper's department are merely open tubes, which are usually suspended over the receiver at a point three or four feet from its end the receiver at a point three or four feet from its end-
This is so adjusted that merely the pressure of the carrier against it opens the valve. The carrier then drops by gravity to the end of the receiver, and is taken out by the cashier's clerk or bookkeeper. As soon as the carrier passes, the valve is shut by a spring, and thus the current is confined. The air is then diterminal, the operation of which has already seending scribed. The return tube to the sales department also terminates in the valve, which is located directly at its mouth. When the carrier is sent back, its impact is sufficient to open this valve, and it drops upon the salesman's table, the valve closing automatically and confining the air current as in the other instances. The system in the cashier's and bookkeeper's department requires some one to take the carriers out, in
order that they may be examined as they are received, thus preventing unnecessary delay in making change. As the extent of the service is limited only by the power of the blower plant, some of the pneumatic systems which have been installed in department stores recently constructed are very extensive. Perhaps the largest in the United States is located in Philadelphia. It consists of over 250 stations, each length. A plant of 150 horse power is utilized, and in all nearly 20 miles of tubes are used. The power is sufficient to force the carriers through every line as rapidly as they can be inserted in the tubes.

Carriers of three and four inches in diameter are employed for transmitting papers and small packages in factories and warehouses, where bulkier material is required to be transferred from one portion to the other. The arrangement of the tubes is the same, and the carriers are received and dispatched according to the same plan, the power plant being of course, correspondingly larger to meet the requirements.

Not only the blower, but the compressed air system is utilized in the long-distance tube service which is employed by the government in New York and other large cities in connection with the Post Office Department. Thus far the plants for transmitting mail have Yerk and Brooklyn by conveying it between New Bridge and between the main post office in New York and the Grand Central Station. Here carriers which are 10 inches in diameter and about 3 feet in length are employed. The most extensive installation of this kind, however, is in operation in Boston, extending from the retail shopping district on Harrison Avenue to Back Bay, South End, Roxbury, Dorchester, and other sub-stations. This system conveys carriers which are 10 inches in diameter. The tube is laid underground, and consists of ordinary cast-iron water pipe finished at the joints in order to make a close fit. It is laid like a water conduit, with lead and iron joints, the curves being of 12 feet radius to the center line. The bends were cast in sections, the standard of $90 \mathrm{de}-$ grees comprising three 30-degree sections bolted together. The carriers which, as might be imagined, were manufactured especially for the purpose, consist of sheet metal riveted together, but move through the tube on wheels, five of which are placed at each door. On account of size and weight, the terminals are of special design. The receiving terminal consists of an air cushion closed at one end by a revolving valve, opened and closed by a cylinder and piston operated by the air from the tube. Ordinarily this valve is closed, but when a carrier enters the receiver, it compresses the air in front of it. This pressure afbrought nearly to rest, the auxiliary overbalances and moves the controlling valve of the main cylinder. This opens the revolving valve, and allows the carrier to roll out. Just at the end of the receiver two vanes are monnted, so that the pressure of the air behind
the carrier tends to move them. This motion is made 
use of to restore the auxiliary valve to normal position and close the receiver. The carrier is placed in
tube by moving valves eonnected with an air lock.

The power for this system, which is over ten mile in length, is compressed air, the service requiring about 1,400 cubic feet per minute, the pressure varying from $13 / 4$ pounds to 2 pounds. Before entering the com calcium chloride, which effectually removes all moist calcium chloride, which effectually removes all moist-
ure. This tank is open to the atmosphere, and the ure. This tank is open to the atmosphere, and the incoming line passes through the tank and returns to the compressor. Only such air has to be dried as is lost through leakage or used for operating the ma chines. The compressors are duplex belt-driven with 21-inch $\times$ 12-inch cylinders. There are two each at the main, South End, and Roxbury stations, and one each at Dorchester and Back Bay. The compressors are driven by 50 horse power, three-phase induction are driven by 50 horse power, three-
motors of the internal resistance type.

The system has been found to be an excellent substitute tor wagons and other methods of delivery, an is largely used by merchants for sending parcels to the residence district:s where sub-stations are located. At these they are sorte.d and distrihuted to the houses of the customers by teams and messengers. It is found that the average time required to deliver packages from the main station to any portion reached by the service is ten minutes, where from forty-five minute to an hour would be required by the usual method of delivery.

The pneumatic postal tube system of New York city has been fully described and illustrated in the column of the Sciextific Anerican.

\section{(C)}

\section{linterest in the Jane Naval war}

To the Editor of the Schexplyll Anerican

I beg to congratulate you on your energy and enterprise in securing the right to publish the series of for supplying your readers you not only deserve cred for such an intensely inthe attention of the nation to a critical state of affairs.

It is true we may never go to war with one of th powerful European nations; but the best way to mak sure of that is to have a fleet that they would dread to encounter. Owing to our late "expansion," we now need two fleets; one in the Atlantic second only to England's, aind one of considerable power in the $\mathrm{P}$ cific.

The "War Game" shows how greatly we would have to weaken our Atlantic fleet if an attack should be made on the Philippines-and there is where it would be made - as far as possible from our home base of supplies.

If civilians are allowed to join the new Naval League I would like to have the honor of becoming a member. Can yo's lindly give me any information about that? I have been looking for some professional criticism of the "Battle of Manila." There seem to be scme lessons of great importance in that engage ment; though I think the Americans were not given ment; though I think the Americans were not given
credit enough for gun fire and probable skill in action. credit enough for gun fire and probable skill in action. One of the lessons is-modernize the "Oregon" class by sulstituting 12 -inch guns for the 13 -inch, lowering the 8-inch turrets so the guns can fire on a line with the keel, and using the weight saved by adding mor 6-inch guns. All 13-inch guns ought to be replaced by 12-inch. Some "semi-battleships" carrying two or four 10-inch guns and not less than twenty 6-inch gun would malse a welcome addition to meet such vessels would make a welcome addition to meet such vessel
as the "Kaiser" class.
B. D. Mercinast.

San Jose, Cal., March 5, 1903.

\section{sately of Lailowy Travel in England.}

To the Editor of the Scintrifle Andisicax:

The awful accidents which one hears of almost daily in this country would be comparatively few if the railroals were operated on the same basis as those of England. There is not a railway in England that is not fitted out with a complete block signaling system. which is worked by an army of trained men, most of whom enter the railway service as boys at fifteen and sixteen years of age, and usually start in the signal boxes or cabins as telegraph learners. They serve two, three, and even four years, until they are thoroughly acquainted with the telegraph instrument and the working of the signal box. when they are drafted cut as relieving signalmen, and are appointed signalcut as relieving signalmen, and are appointed signal-
men whenever a vacancy arises. A man when once appointei to a box usually holds the same position for quite a number of years, so that he is able to get thoroughly conversant with everything around him. He has to have good eyesight and hearing, being examined for this alout every two years. The signals and points mostly all work together by means of an interlocking arrangement, so that when the switch or point is pulled the signal is pulled at the same time.
Nearly every country station has its signal cabin or box with signalmen always on duty. These usually have twelve-hour shifts, but in busy yards they wor on eight-hour shifts. On single-line roads, or what are termed "branch lines," they work by what is called the "train tablet system." With this system it is impessible from the rangement from one signal box to the other, and the enrangement from one signal box to the other, and the en-
ginemen of the trains before starting on their journeys on a single road are compelled, under penalty of instant dismissal, to see that they have the train tablet hande to them by a responsible person and fixed in a secure position on the footplate, where they can see it. Whe they reach the next section they have to deliver one tablet and receive another. Trains running in an opposite direction they pass at stations booked in their time table book, or, if trains are running late, ar rangements are made accordingly. so that uncler this system it is almost impossible for a collision to occur. In nearly every branch of the railway service a man has to start at the bottom and be trained up to the more responsible positions; but at busy times whe traffic is heavy, most railways employ supernumeraries to do less important duties. The hours of enginemen and firemen are not to exceed ten to twelve hours on duty, so that there is no chance of their being overworked. The officers of the various department have to draw up weekly reports of hours worked by railway servants and these are sent in to the Board of Trade authorities.

Now as to the keeping up of the roadbeds, bridges, culverts, etc. There are district engineers appointe for so many miles of road, which is divided up into sG many sections. Each section is kept in good wor ing order by five men, the foreman, platelayer or "ganger," as he is termed, and four men to work under him. One of the ganger's most important duties is to traverse the entire length of his section every day to see that everything is all right and to report an serious defect in the road or bridges, etc., to his dis trict engineer, who then informs the heads of the various departments, who issue out printed forms to all persons concerned, so that they can be on the lookout and be prepared to stop if required to do so. On nearly every railway there is a man to about every mile of road, so that it gives them a good chance to keep the road in thorough repair. Should a collisio or railway accident of any kind occur, there is a Boar of Trade investigation, presiled over by Major Mari den or Colonel York, to determine the cause and the persons respcinsible for it. The very few accident that take place around London, where the traffic is so thick, especially at Waterloo Station, during the Derby, Ascot, and Kempton Park race days, when trains are arriving and departing every minute or so, is truly remarkable, particularly since London is subject to heavy fogs. These, however, they are always prepare for. by having the platelayers do their part as groun signalmen to lay the detonators or torpedoes when reguired, so as to warn

Now as to the important duties of the enginemen. The engineer is supposel to keep a strict lookout fo all signals, and the fireman is to assist him in doin the same when not engaged in firing up or puttin water in the boiler, etc. The rules require fireme to do these duties as far as pGissible between station especially on express trains, and to be on the lookout for signals on approaching stations and junctions, so that if the engineer did not catch sight of the signals the fireman would, especially when traveling by night. the fireman would, especially when traveling by night. Then again there are issued, every three months, time
table books for the drivers and firemen. At the heal of each leaf of the book the following is printed of each leaf of the book the following is printed
"Time must not be made up in running down incline and the men are supposed not to take any chances whatever." When an engineman is leaving a statio with his train he is supposed to look back and see that the entire train is following and be prepared to stop if signaled to do so. All these things go towar making the safety of the traveling public complete as shown by the fact that not a single life was lost on British roads last year. At.FREI T. LANCASIIIRE. Little Valley, N. Y., March 7, 1903.

\section{A Coal Substitute.}

To the Editor of the Scientific A mierican:

As a coal famine is subject to occur in the future possibly the following regarding cheap fuel might be of use to the public in districts where the material is found to exist.

While living in South Wales we used to send to neighboring pit for a horse load of slack coal. costin 60 cents. This we mixed with two-thirds clay (du up near the house) in the form of mortar. and the turned it out by hand into balls three or four inche in diameter. These, when dry or nearly so, we placed on already started coal fires for heating rooms. coal at the time being extremely rheap and handier for cooking. They became like balls of red-hot iron, giv

ng out great heat and lasting about twenty-four ours, when they crumbled to ashes. The fire was renewed by placing more on top and making a fuel a.j may be seen, costing only 20 cents the ton.

Now it occurs to me this peculiar clay (no doubt some vegetable substance) must exist in many parts of the North American continent, probably in large quantities, possibly beneath the entire prairies, among mountains, veneath some kind of swamps, and overlying coal fields. Also that it can be made to burn by mixture with some other material, such as sawdust peat, or finely chopped straw or cornstalks.

For those living inconvenient distances from coat mines or wanting cheap fuel, I would suggest experimenting with any kind of clay they think might have these properties. It will cost little time or trouble It would be easy for the government to import one or two hundred pounds from the same spot for analysis. To any one communicating direct I will give such fur ther information as lies in my power.

Chaworth, London South, Ontario, February 14, 1903

The Designing or the "connecticut."

To the Editor of the Sciestific Anierican

In view of the fact that the General Board of the Navy has unanimously advised Congress to have our future battleships follow the lines of the "Connecticut" class, it would be interesting to examine this design and see if advantageous changes are possible. Th design for the "Connecticut" is probably the finest piece of work of its kind that has ever been turned out here or abroad and the action of the English Admiralty in discarding completely their own previous designs, and practically copying the "Connecticut" for their latest and largest battleships, is a great com pliment to our designers.

In looking first at the armament of this battleship, it shows up both enormously powerful and excellently proportioned; nevertheless it looks like a mis take to reduce the length of her 8-inch guns from 45 to 40 calibers, and 100 rounds per 7 -inch rapid-fire gun does not seem sufficient.

The writer thinks that these two items should be changed, even if it should be necessary to omit two or even four of the 3-inch guns and their ammunition supply. This could be done without materially impairing the fighting efficiency.

In regard to the protection, the results do not apthe side is covered with 6-inch armor only; and in view of the fact that foreign navies are increasing the sizes of their broadside guns, and that the thickness of the casemate armor on the latest designs in England is 9 inches and 7 inches, this is too light.

It would be possible, by slightly modifying the plans, to carry a casemate belt of $7 \%$-inch uniform thicknes extending from the main belt to the main deck, with athwartship armor of the same thickness by proceeding as follows:

Stop the lower casemate belt at the same point that the upper stops at now, and carry the lower athwartship armor across to meet the barbettes just under the upper. This will result in a saving in length of both the lower casemate and lower athwartship belt, and on one side of the ship would amount to about 54 square feet of 6 -inch armor, equivalent to 3,275 squar feet of 1-inch armor.

Next dispense entirely with the 2-inch nickel steel protection to the 3-inch guns; lattle experience having shown this class of armor to be dangerous, it not being sufficiently thick to exclude common shell from guns of 6 inches and above, and would only serve to make the explosion of such shells more disastrous. Thi wculd save about 700 square feet of 2 -inch armor or 1,400 square feet of 1 -inch, making a total saving of 4.675 square feet of 1 -inch armor

To increase the thickness of the casemate and ath wartship lelts to a uniform $71 / 2$ inches, would require about 2.420 sqrare feet of $1 \%$-inch armor and 1.630 square feet of $1 \%$ inch, equivalent to 4,450 square feet of 1-inch armor.

This proness would leave a margin of 225 square feet of 1-inch armor for each broadside, and for the whol ship would save about 8 tons in weight.

The barbottes would have to be changed to meet the above conditions, making the face outside of the $7 \%$ inch armor 10 inches thick, and the portion inside $t$ inches thick.

This would involve a very slight increase in weight, which could be deducted from the surplus 8 tons.

The proposed changes would lower the position of the center of gravity of the masses involved about feet, and would apparently add to the efficiency of the ship.

Note.-The above discussion is based on the plans submitted by Admiral Bowles to the Society of Naval 